\title{
Influence of Chest Wall Distortion and Esophageal Catheter Position on Esophageal Manometry in Preterm Infants
}

\author{
GALDINO SILVA NETO, TILO O. GERHARDT, NELSON CLAURE, SHAHNAZ DUARA, AND \\ EDUARDO BANCALARI
}

Division of Neonatology, Department of Pediatrics, University of Miami School of Medicine, Miami, Florida \begin{abstract}
The purpose of this study was to determine the effect of chest
wall distortion on esophageal manometry by measuring simultaneous esophageal pressure changes at two sites in preterm infants. Fourteen infants were studied (mean \pm SD: birth weight, $1340 \pm 260 \mathrm{~g}$; age, $8.5 \pm 4 \mathrm{~d}$ ). Esophageal pressure was measured through two water-filled catheters, one placed just above the cardia (Pes1) and the other at the level of the carina (Pes2). Chest wall distortion was measured by inductance plethysmography, and inspiratory and expiratory flow by pneumotachography. No significant differences were found between the peak to peak esophageal pressure changes measured through the lower and higher catheters during both airway occlusion (18.7 \pm 4.4 versus $18.3 \pm 2.6 \mathrm{~cm} \mathrm{H}_{2} \mathrm{O}$ ) and spontaneous breathing (9.4 \pm 1.8 versus $9.0 \pm 1.8 \mathrm{~cm} \mathrm{H}_{2} \mathrm{O}$ ), although half of the infants had significant chest wall distortion. Mean pulmonary compliance and resistance measures calculated from the two pressures for individual infants showed small differences consistent with the difference between Pes1 and Pes2. For the whole group of 14 infants, however, these differences were not significant. The
\end{abstract}

pressure changes from the lower and higher measuring sites for each breath were analyzed using linear regression. The weighted average of the mean slopes of the 14 infants was significantly different from 1.0 (mean \pm SD: $0.92 \pm 0.10$, range: $0.75-1.10$; $p<0.05$ ). In some of the infants, the slopes for different breaths were not consistent, but varied from breath to breath. Neither this breath to breath variability in the relationship between Pes1 and Pes2, nor the mean slopes were related to the degree of chest wall distortion. The results indicate that esophageal pressure measurements in preterm infants are not as dependent on the position of the catheter tip and the degree of chest wall distortion as previously suggested. A tip positioned between the cardia and the level of the carina transmits pleural pressure changes reliably. (Pediatr Res 37: 617-622, 1995)
Abbreviations
Pes, esophageal pressure change (peak to peak)
PS, phase shift
TCD, total compartmental displacement

The determination of pulmonary compliance and resistance in spontaneously breathing infants requires reliable measurements of pleural pressure changes simultaneously with tidal flow and volume. From observations made in adults and experimental animals it is assumed that esophageal pressure changes accurately reflect changes in pleural pressure (1-3). This assumption can easily be tested clinically by occluding the airway at its opening. The resulting tidal pressure swings in the airway almost equal the pleural pressure swings because both alveolar volume change and gas flow in the airways are minimal, so that pressure losses from overcoming elastic and resistant forces are negligible. Esophageal pressure swings recorded simultaneously are of similar magnitude as the pressure changes measured at the airway opening indicating that

Received August 10, 1994; accepted December 22, 1994.

Correspondence: Tilo Gerhardt, M.D., University of Miami School of Medicine, Department of Pediatrics (R-131), P.O. Box 016960, Miami, FL 33101.

Supported by the University of Miami: Project Newborn. pleural pressure changes are well transmitted to the esophagus $(4,5)$

In contrast to adults, esophageal manometry in neonates is more variable, and the measurements of compliance and resistance are often not reproducible $(6,7)$. Although some investigators describe a good correlation between airway and esophageal pressure in neonates during airway occlusion $(8,9)$, others have found this correlation highly variable $(6,7)$. A difference between airway and esophageal pressure changes during occlusion has been observed especially in infants with lung disease (6) and chest wall distortion (10). It has been theorized that chest wall distortion leads to an unequal distribution of pleural pressure and that esophageal pressure, as a consequence, may not reflect mean pleural pressure changes (10). This interpretation is supported by the observation that the relationship of esophageal to airway pressure during airway occlusion may vary with the position of the tip of the esophageal catheter (10).

This study was designed to ascertain if recorded pressure changes during chest wall distortion depend on the position of 
the catheter tip in the esophagus. This was done by measuring esophageal pressure simultaneously at two different sites and documenting the influence of chest wall distortion on the difference between the two measurements.

\section{METHODS}

Fourteen preterm infants were studied. Five infants did not have clinical evidence of lung disease and thus had not been intubated, whereas the rest had recovered from hyaline membrane disease and mechanical ventilation. All infants were breathing room air spontaneously on the day of the study. To measure esophageal pressure at two sites simultaneously, two size $8.0 \mathrm{Fr}$ feeding tubes were inserted into the esophagus. The tubes were taped together so that their tips were either 3.0 or $4.0 \mathrm{~cm}$ apart. The intent was to have the lower tube positioned in the lower esophagus just above the cardia and the upper tube at the level of the carina. To achieve this, a distance between the tips of $3.0 \mathrm{~cm}$ was used in infants $<1000 \mathrm{~g}$ and a distance of $4.0 \mathrm{~cm}$ in neonates $>1000 \mathrm{~g}$ birth weight. The tubes were advanced until the tip of the lower one was in the stomach as determined by positive pressure deflections with each inspiration. They were then withdrawn until the lower tube produced consistent negative deflections during inspiration, and subsequently fixed in place. The tubes were connected to pressure transducers (Spectramed P23XL pressure transducer, volume displacement $0.0004 \mathrm{~mm}^{3} / \mathrm{mm} \mathrm{Hg}$; Spectramed, Inc., Oxnard CA) and filled with distilled water. Both catheters were flushed before each recording to prevent secretions or gas bubbles from accumulating at the tips. Airway pressure was measured using a similar transducer connected to a side port in the nasal prongs.

The tubes connecting the transducers to the site of measurement were of equal length. The pressure transducers were powered by signal conditioners (Gould Transducer Coupler, Gould, Inc. Cleveland, $\mathrm{OH}$ ) with less than $2 \%$ noise to signal ratio at maximal sensitivity. Calibration was performed before each test by simultaneously exposing the transducers to the same input pressure, determined by a water manometer, and adjusting the amplifiers to give the same output. There was no phase difference between the signals and no over- or underdampening of the signal up to $10 \mathrm{~Hz}$. The output of the transducers was linear between +20 and $-20 \mathrm{~cm} \mathrm{H}_{2} \mathrm{O}$ as determined during the calibration procedure.

Respiratory flow was measured with a Fleish OO pneumotachograph (OEM Medical, Richmond, VA) and a Validyne differential pressure transducer (model MP45, $\pm 2 \mathrm{~cm} \mathrm{H}_{2} \mathrm{O}$, Validyne Engineering Corp., Northridge, CA). We tested the ouput of the pneumotachograph and found it to be linear form 0 to $0.1 \mathrm{~L} / \mathrm{s}$. Its frequency response was flat up to $10 \mathrm{~Hz}$. The flow signal was calibrated using constant known flows measured with a flowmeter (Matheson Gas Products, model 2800 , Secaucus, NJ). The pneumotachograph was connected to the airway via nasal prongs using petroleum jelly to prevent leaks around the prongs. The total system has a dead space of 2.2 $\mathrm{mL}$. The mandible was supported by gentle pressure to eliminate mouth breathing and prevent upper airway obstruction.
Chest wall and abdominal displacemnt were measured by inductance plethysmograph (Respigraph NIMS, Miami Beach, FL). The rib cage band was placed around the upper thorax with its upper rim in the axilla and its lower rim over the manubrium sterni. The abdominal band was placed over the umbilicus with its upper rim below the costal margin and the lower rim above the pelvis. Both bands were secured in place by tape. A semiquantitative calibration was performed over 5 min and verified by the synchrony between the onset of inspiratory flow and the sum signal of the two bands (11). Furthermore, an airway occlusion test was performed during which the sum signal decreased to zero.

The signals from the bands were digitized at a sampling rate of $100 \mathrm{~Hz}$ and stored on computer for analysis (IBM, PC-386). A computer program calculated the PS between the two wave forms, and computed TCD ratio (12). This is the ratio between the sum of the absolute values of rib cage and abdominal displacement (entering a negative chest wall movement as positive) divided by the true sum of both values. With synchronized undistorted breathing, the TCD ratio is 1.0 and increases above 1.0, depending on the degree of chest wall distortion. The signals of flow and pressure were also digitized at $100 \mathrm{~Hz}$ and stored for analysis.

Airway occlusion was performed manually at the end of expiration. The peak deflections from the two esophageal catheters occurring with each inspiratory effort were identified and related to the accompanying airway pressure change as reference. Equal changes in esophageal and airway pressures indicate complete transmission of pleural pressure to the measurement site in the esophagus and are used as a test of accurate function for the esophageal manometry system $(4,5)$.

In addition, peak to peak pressure changes from the esophageal tubes were analyzed and compared during unoccluded spontaneous breathing. For each breath, linear regression analysis was used to assess the relationship between the two simultaneously recorded pressure signals from the two sites in the esophagus. The slope of this relationship indicates possible differences in pressure changes recorded from the two measurement points. A slope of 1.0 would indicate equal pressure changes in the lower and middle section of the esophagus.

Tidal volume was obtained by digital integration of flow. Pulmonary compliance and total inspiratory and expiratory resistance were calculated by a computer program based on the equation of motion. The method has been described previously and has been modified by us $(13,14)$. Calculations of pulmonary compliance and resistance were performed separately using the esophageal pressure recorded through either the lower catheter (Pes1) or the higher catheter (Pes2).

After the esophageal tubes were in place, the infants were observed until they fell asleep and were breathing regularly. Then the nasal prongs with the pneumotachograph were inserted and the infants were allowed to adapt to the stimulatory effect of the prongs until they showed regular breathing with minimal variability in tidal volume. Only then were the respiratory signals recorded for approximately $1 \mathrm{~min}$. No recordings were done when the infants were moving, or if they showed signs of arousal or agitation. 
Of approximately 60 breaths recorded in each infant, $10-15$ were selected to be included into the statistical analysis. This selection was determined by the mechanical properties of each breath that had to meet the following criteria for the computer program to give a correct estimate of compliance and resistance: 1 , a difference between inspiratory and expiratory tidal volume of less than $10 \% ; 2$, the same level of zero or baseline esophageal pressure at the beginning and end of the breath for both measurement sites; and 3, a correlation coefficient $>0.95$ to calculate compliance and resistance by linear regression analysis of tidal flow and pressure. Measurements of compliance and resistance based on pressures obtained from both the lower and higher sites must fulfill this criterion.

Statistical methods. Descriptive statistics were calculated for all variables. Histograms were used to assess or approximate normality. Scatter plots were used to assess the linearity of the relationship between two variables and to detect the presence, if any, of outliers. Comparisons of measurements obtained from the two catheters were made using a paired $t$ test or its nonparametric counterpart, the Wilcoxon test, when the assumption of normality was not tenable. Pearson correlation analysis was used to assess the relationship between indices of chest wall distortion (PS or TCD ratio) and either the difference between the two pressure measurements or the slope of the regression of Pes1 on Pes2.

Because repeated measurements were done of several variables for each infant, we used each infant's mean values rather than individual measurements for whole group analyses. Inasmuch as the number of measurements varied from individual to individual, each infant's mean was weighted using the inverse of its variance as weight.

Approval for the study was obtained from the Committee for the Protection of Human Subjects at the University of Miami. Informed consent was obtained for each of the infants tested.

\section{RESULTS}

Table 1 presents means $( \pm \mathrm{SD})$ and ranges of some of the characteristics of the infants studied, including birth weight, gestational age, and weight and age at the time of study.

Airway occlusion. During airway occlusion, the mean peak to peak esophageal pressure changes measured from the lower and higher catheters were $18.7 \pm 4.4$ and $18.3 \pm 2.6 \mathrm{~cm} \mathrm{H}_{2} \mathrm{O}$, respectively. The difference between these means was not significant. The mean change in airway pressure during these occlusions was $17.8 \pm 3.6 \mathrm{~cm} \mathrm{H}_{2} \mathrm{O}$. The ratio of esophageal to airway pressure was $1.05 \pm 0.09$ for the lower site of pressure measurement and $1.04 \pm 0.09$ for the higher site, a nonsignificant difference.

Esophageal pressure changes during unoccluded breathing. The mean peak to peak tidal pressure changes recorded

Table 1. Characteristics of the infants studied $(n=14)$

\begin{tabular}{lcc}
\hline \multicolumn{1}{c}{ Characteristic } & Mean \pm SD & Range \\
\hline Birthweight (g) & $1350 \pm 250$ & $925-1715$ \\
Gestational age (wk) & $31.5 \pm 2.2$ & $28-35$ \\
Age (d) & $8.7 \pm 3.9$ & $3-15$ \\
Study weight (g) & $1300 \pm 290$ & $780-1680$ \\
\hline
\end{tabular}

from the lower (Pes1) and higher (Pes2) sites in the esophagus are shown for each infant in Table 2. In six of the 14 infants, Pes1 was significantly higher than Pes2; in two infants the reverse was true; in the remaining six, no significant differences were evident between Pes1 and Pes2. For the whole group of 14 infants, the difference between Pes1 and Pes2 was not significant.

In each infant, the correlation between peak to peak esophageal pressure changes obtained in the two positions was greater than 0.95 . The mean slopes of the linear regression of Pes1 on Pes2 varied between 0.75 and 1.10 for the individual infants. Eleven of the fourteen showed a slope significantly different from 1.0: in two infants the slope was significantly higher than 1.0 and in the remaining nine it was lower than 1.0.

The average slope for all 14 infants was 0.92 and significantly different from $1.0(p<0.05)$. Measurements from the lower esophageal catheter were slightly higher than the recording from the higher catheter.

Measurement of compliance and resistance. The results of compliance and resistance measurements obtained by using the pressure changes observed either in the lower esophageal site (Pes1) or the higher site (Pes2) show a pattern similar to the differences between Pes1 and Pes2 presented above. Just as Pes1 and Pes 2 were not significantly different in approximately half of the infants, no significant differences were found between the two compliance or resistance measurements in these same infants. Similarly, among the remaining infants where differences were found between Pes1 and Pes2, differences between the two measures of compliance and resistance were also significant.

For the whole group, the measurements based on the pressures obtained from the lower catheter (Pes1) showed a slightly lower compliance and higher resistance than the measurements based on Pes2 (higher position catheter). The differences became significant only for expiratory and total compliance and for inspiratory resistance (Table 3).

There was no significant correlation between PS or TCD ratio and slope in individual infants. The absence of any detectable effect of PS or TCD ratio on the slope or the difference between Pes1 and Pes2 is illustrated in Figures 1 and 2.

Figure 1 shows recordings of esophageal pressure in an infant with chest wall distortion. The two pressures recorded in the lower and higher sites in the esophagus, however, do not show a consistent difference and have a nearly identical deflection in two of the three breaths. Figure 2 shows perfect synchrony between rib cage and abdomen. The slope between the two pressures, however, varies because the pressure transmission to the higher measurement site (Pes2) decreases during some of the breaths. This change in pressure transmission is not related to a change in breathing pattern or degree of chest wall distortion.

Figures 3 and 4 illustrate this point for the whole group of infants. The mean slopes obtained by linear regression of Pes1 on Pes2 in individual infants do not show any correlation to TCD ratio or PS, although half of the infants had a clinical significant (TCD ratio $>1.5$ ) and highly variable degree of chest wall distortion. 
Table 2. Peak to peak esophageal pressure change measured in the lower (Pes1) and the higher (Pes2) position in each of 14 infants and slope of the regression of Pes1 on Pes2 (Means $\pm S D$ )

\begin{tabular}{|c|c|c|c|c|c|}
\hline $\begin{array}{c}\text { Patient } \\
\text { no. }\end{array}$ & $\begin{array}{c}\text { Pes1 } \\
\left(\mathrm{cm} \mathrm{H} \mathrm{H}_{2} \mathrm{O}\right)\end{array}$ & $\begin{array}{c}\text { Pes2 } \\
\left(\mathrm{cm} \mathrm{H} \mathrm{H}_{2} \mathrm{O}\right)\end{array}$ & $p$ value* & Slope & $p$ value $f$ \\
\hline 1 & $13.1 \pm 1.3$ & $12.9 \pm 2.4$ & NS $\ddagger$ & $0.97 \pm 0.15$ & NS \\
\hline 2 & $9.6 \pm 0.8$ & $9.1 \pm 0.7$ & 0.003 & $0.89 \pm 0.05$ & 0.000 \\
\hline 3 & $8.5 \pm 1.8$ & $8.6 \pm 1.5$ & NS & $0.98 \pm 0.08$ & NS \\
\hline 4 & $6.8 \pm 1.0$ & $7.7 \pm 1.0$ & 0.000 & $1.08 \pm 0.05$ & 0.000 \\
\hline 5 & $10.3 \pm 0.9$ & $9.9 \pm 1.1$ & NS & $0.92 \pm 0.05$ & 0.000 \\
\hline 6 & $8.6 \pm 1.3$ & $6.8 \pm 1.3$ & 0.000 & $0.75 \pm 0.05$ & 0.000 \\
\hline 7 & $13.0 \pm 1.8$ & $12.1 \pm 2.1$ & 0.011 & $0.82 \pm 0.09$ & 0.000 \\
\hline 8 & $8.7 \pm 1.0$ & $7.8 \pm 1.0$ & 0.000 & $0.88 \pm 0.12$ & 0.013 \\
\hline 9 & $7.0 \pm 0.8$ & $8.2 \pm 0.7$ & 0.000 & $1.10 \pm 0.13$ & 0.010 \\
\hline 10 & $8.9 \pm 2.1$ & $7.0 \pm 1.4$ & 0.000 & $0.77 \pm 0.02$ & 0.000 \\
\hline 11 & $9.3 \pm 2.3$ & $9.0 \pm 1.6$ & NS & $1.00 \pm 0.18$ & NS \\
\hline 12 & $9.5 \pm 1.8$ & $9.3 \pm 1.8$ & NS & $0.96 \pm 0.07$ & 0.037 \\
\hline 13 & $9.2 \pm 1.0$ & $9.4 \pm 1.0$ & NS & $0.88 \pm 0.04$ & 0.000 \\
\hline 14 & $8.8 \pm 1.5$ & $7.8 \pm 0.9$ & 0.016 & $0.86 \pm 0.10$ & 0.002 \\
\hline Mean & $9.4 \pm 1.8$ & $9.0 \pm 1.8$ & NS & $0.92 \pm 0.10$ & 0.013 \\
\hline
\end{tabular}

* $p$ value for the difference between Pes 1 and Pes 2 was analyzed by paired $t$ test.

$\dagger p$ value for the slope being different from 1.0 was analyzed by a one group $t$ test.

$\ddagger$ NS, not significant.

\section{DISCUSSION}

The results demonstrate that mean peak to peak esophageal pressure changes recorded simultaneously at two different sites 3-4 $\mathrm{cm}$ apart were not significantly different during airway occlusion in this group of 14 preterm infants. Similarly, during unoccluded breathing the difference between the two pressures $\left(0.32 \mathrm{~cm} \mathrm{H}_{2} \mathrm{O}\right)$ was not significant. In the latter case, however, the slope of the relationship between the two pressures $(0.92)$ was significantly different from 1.0. In approximately half of the infants, Pes1 (lower catheter position) differed significantly from Pes2 (higher catheter position in the esophagus).

Differences found in the two compliance and resistance values when comparing the measurements based on the esophageal pressure recordings from both the lower and higher sites were determined by the differences in the two pressures. Because all differences were small and well within the inter- and intrapatient variability for neonates, they are probably not of clinical importance $(15,16)$.

The majority of infants showed significant chest wall distortion and phase lag between the movements of abdomen and rib cage. Despite this considerable and variable chest wall distortion, no effect of distortion on the difference in pressure recorded from the two sites in the esophagus could be documented. A difference between the two pressures developed in

Table 3. Means $\pm S D$ of compliance and resistance

\begin{tabular}{|c|c|c|c|c|}
\hline \multirow[b]{2}{*}{ Variable } & \multirow[b]{2}{*}{ Type } & \multicolumn{2}{|c|}{ Site } & \multirow[b]{2}{*}{$p$ value } \\
\hline & & Lower & Higher & \\
\hline \multirow{3}{*}{$\begin{array}{c}\text { Compliance } \\
\text { (ml/cm } \\
\left.\mathrm{H}_{2} \mathrm{O} / \mathrm{kg}\right)\end{array}$} & Total & $1.24 \pm 0.47$ & $1.37 \pm 0.43$ & $<0.05$ \\
\hline & Inspiratory & $1.26 \pm 0.61$ & $1.30 \pm 0.49$ & NS* \\
\hline & Expiratory & $1.17 \pm 0.55$ & $1.28 \pm 0.52$ & $<0.05$ \\
\hline \multirow{3}{*}{$\begin{array}{l}\text { Resistance } \\
\qquad\left(\mathrm{cm} \mathrm{H}_{2} \mathrm{O} / \mathrm{L} / \mathrm{s}\right)\end{array}$} & Total & $91 \pm 28$ & $85 \pm 28$ & NS \\
\hline & Inspiratory & $75 \pm 31$ & $66 \pm 31$ & $<0.05$ \\
\hline & Expiratory & $112 \pm 32$ & $107 \pm 29$ & NS \\
\hline
\end{tabular}

Analysis based on esophageal pressure measurements in the lower and higher sites.

${ }^{*}$ NS, not significant. the absence of any chest wall distortion, and the occurrence of chest wall distortion could be observed without any change in the difference between the two pressures.

Several investigators have stressed the difficulties in obtaining reproducible esophageal pressure measurements in small preterm infants, especially during respiratory distress $(6,7)$. Those studies were done with esophageal balloons, which frequently stimulate peristalsis and gagging because of their relatively large size in relation to the esophagus of preterm infants (17). An increase in esophageal tone and elastance dampens pleural to esophageal pressure transmission espe-
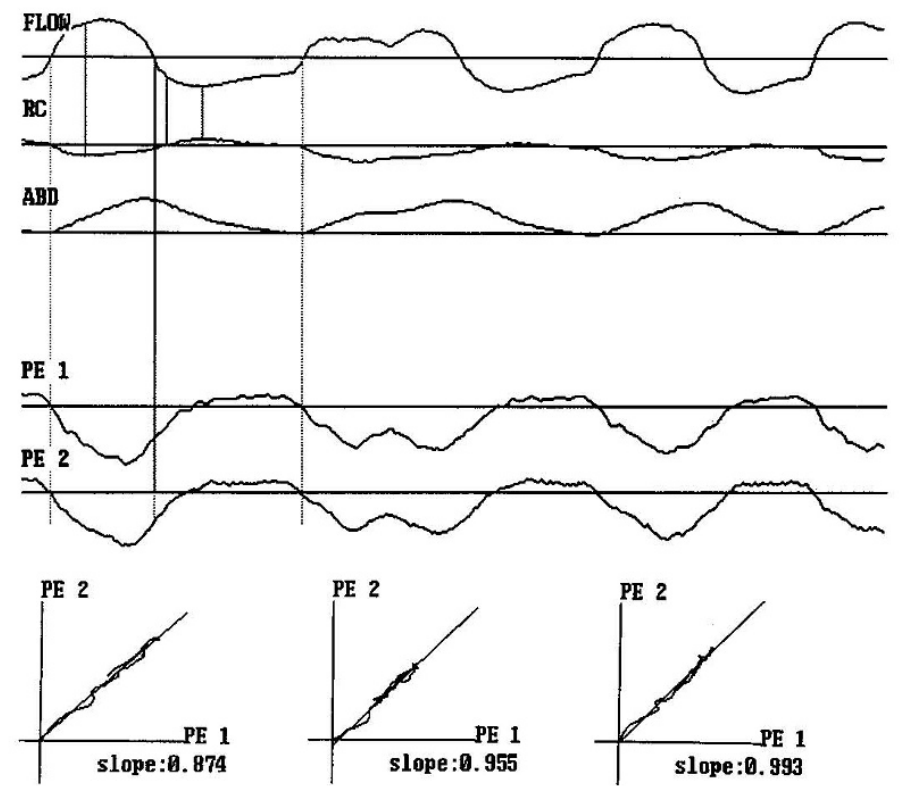

Figure 1. Flow, excursion of rib cage $(R C)$ and abdomen $(A B D)$, and esophageal pressure changes in the lower $(P E I)$ and higher $(P E 2)$ catheter position are shown in an infant with substantial rib cage distortion (TCD ratio = 2.5-3.0). Despite the distortion, the esophageal pressure changes at the two measuring sites do not show a consistent difference and can be of equal size as indicated by the relationship between the two pressures (slope) being close to 1.00 . 

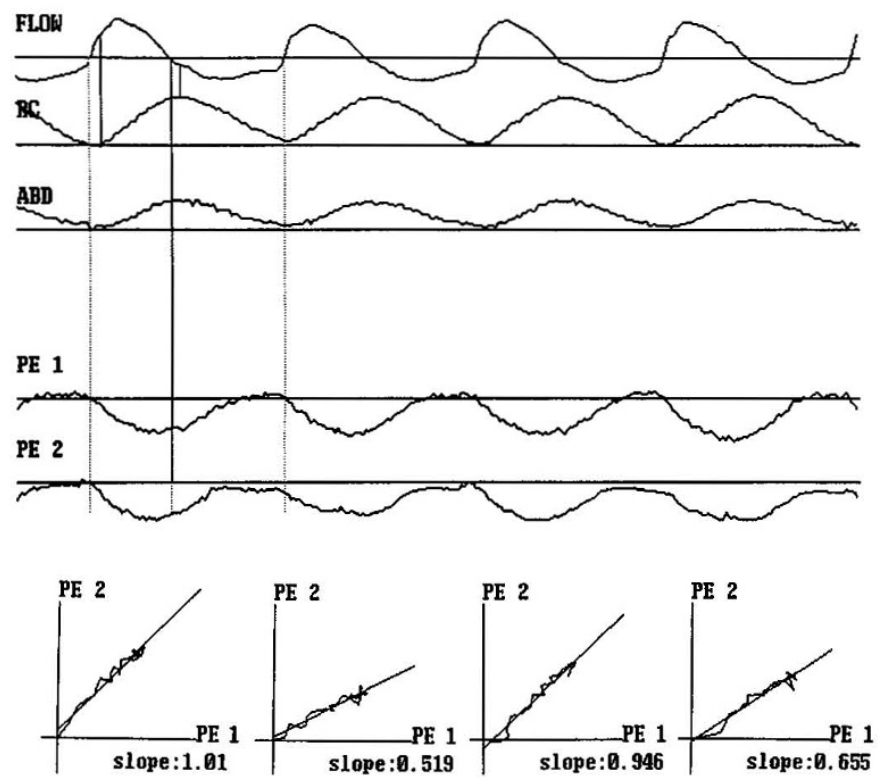

Figure 2. Flow, excursion of rib cage $(R C)$ and abdomen $(A B D)$, and esophageal pressure changes in the lower $(P E 1)$ and higher ( $P E 2)$ catheter positions are shown in an infant with minimal rib cage distortion $(\mathrm{TCD}$ ratio $=1.0-1.1)$. In the first breath, PE 1 and PE 2 are of nearly identical magnitude as reflected by the relationship between the two pressures (slope) of 1.01 . The second breath shows a dampened PE 2 resulting in a decrease in slope. In the third breath, pressure changes of PE 2 have increased to similar magnitude as PE 1, but in the fourth breath PE 2 is damped again. These changes in the relation between the two pressures occur without any change in breathing pattern or degree of chest wall distortion.

cially for a balloon system where the volume changes for a certain pressure transmission are much larger than for a fluid filled system. Other difficulties with the esophageal balloon technique, such as failure to position the balloon properly and movement of the gas bubble in the balloon during the measurements, have been discussed by Coates and Stocks (17). All of these conditions contribute to an increased variability in the measurements.

In contrast to the above experience, investigators using a fluid filled system had results that were more readily reproducible. Asher et al. (8) found esophageal pressure and mouth

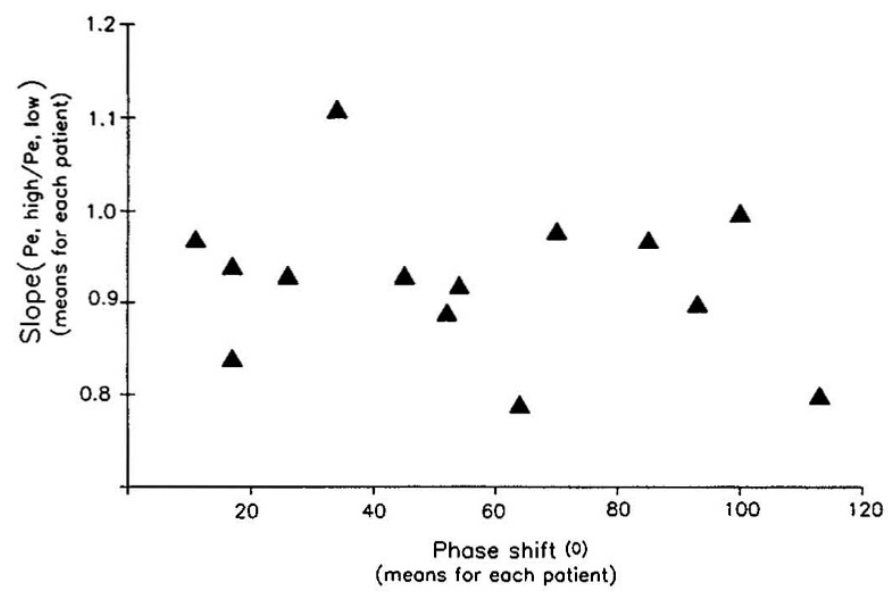

Figure 3. Scatter diagram of thoracoabdominal asynchrony (PS) and slope of the regression of Pes1 on Pes2. Each symbol indicates the means of at least 10 breaths for one of the 14 infants.

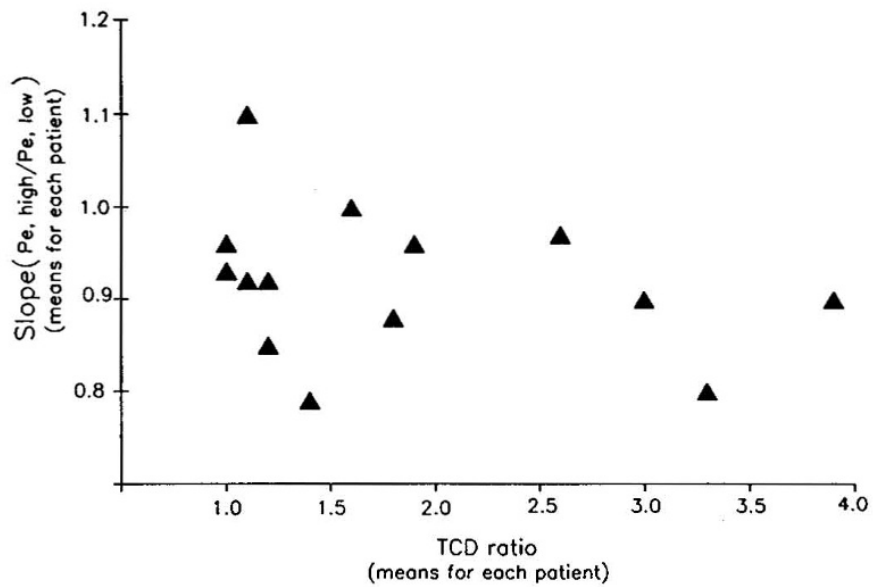

Figure 4. Scatter diagram of chest wall distortion (TCD ratio, see text for definition) and slope of the regression of Pes1 on Pes2. Each symbol indicates the means of at least 10 breaths for one of the 14 infants.

pressure close to unity during airway occlusion in full term neonates, and Coates et al. (9) found a region in the esophagus where esophageal pressure equaled mouth pressure during occlusion in preterm infants with chest wall distortion. These results are similar to the present observation of equal peak to peak pressure transmission from a point just above the cardia and a point $3-4 \mathrm{~cm}$ higher, both pressure swings being closely correlated to airway occlusion pressure.

As shown by Coates et al. (9) and also observed by us, during airway occlusion the ratio of esophageal pressure to airway pressure was not fixed but varied around the mean. This became evident when repeating the occlusions several times. A higher airway than esophageal pressure deflection may therefore not always indicate an improper position of the catheter with the need to move its tip to a different position, but may simply be secondary to a transient impedance of pressure transmission. If the difference persists, a mechanical problem of pressure transmission (bubbles, saliva) should be suspected rather than the need to change the position.

Le Souëf et al. (10) measured esophageal pressure changes in preterm infants with chest wall distortion and described a caudocephalad decrease in pressure transmission. In the presence of chest wall distortion, esophageal pressure changes were larger than airway pressure changes when the catheter tip was just above the cardia during the airway occlusion maneuver. The ratio decreased with the catheter tip $4 \mathrm{~cm}$ above the cardia and approached unity in some of the infants. The investigators attributed their findings to an unequal distribution in pleural pressure caused by chest wall distortion, the pleural pressure changes measured close to the diaphragm being larger than the pressure deflection beneath the distorted area. This interpretation is frequently cited as a reason for the variability in esophageal manometry and the inaccuracy of pulmonary mechanics measurements in preterm infants $(15,18,19)$.

Our findings measuring esophageal pressure at two sites simultaneously in a group of preterm infants of similar birth weight and gestational age as in the study of Le Souëf $e t$ al. (10) do not support this interpretation. Nor is this interpretation supported by two recent studies $(9,16)$. Ratjen and Wiesemann (16) found the variability of compliance measurements in 
preterm infants independent from catheter position. Coates et al. (9) documented that, in preterm infants with chest wall distortion, esophageal and airway pressure changes were equal when the catheter tip was between cardia and level of the carina. The latter investigators postulate that the elevated esophageal to airway pressure ratio observed during chest wall distortion by Le Souëf $e t a l$. might be secondary to a reduced transmission of alveolar pressure to the upper airway that is caused by airway narrowing or closure during the occlusion.

A persistent difference between the two pressures recorded from the lower and higher position in the esophagus may be secondary to saliva accumulating in the tip of a catheter, or a small gas bubble in the pressure line dampening signal transmission through one of the catheters. These events should have a similar chance of occurring in either of the two catheters and their effect on the pressure measurements of all 14 infants should balance out. The results, however, suggest a somewhat lower pressure transmission from the higher catheter. This may be explained by the tip of the higher catheter being positioned behind the membranous portion of the trachea in some of the cases. Such a position may dampen full pleural pressure transmission to the esophagus because part of the esophageal wall is not exposed to negative pleural pressure but to atmospheric airway pressure. This interpretation is supported by the observation that during airway occlusion, when airway pressure is also negative, no differences between pressure measurements from the lower and higher catheters were detected.

The slopes of the linear regression of Pes1 on Pes2 were not uniform but varied from breath to breath in some infants (Fig. 2 ). As has been shown, this variability was not secondary to chest wall distortion. We speculate that it may be secondary to a periodic or erratic increase in esophageal tone, which impedes pleural pressure transmission to the catheter tip. If this variability in pressure transmission occurs, it will produce high intrapatient variability in pulmonary function measurements in some infants. Further studies are necessary to elucidate this point.

In conclusion, esophageal pressure measurements in preterm infants with chest wall distortion are not as dependent on the position of the catheter tip as previously suggested. A tip positioned between the cardia and the level of the carina transmits pleural pressure changes reliably.

\section{REFERENCES}

1. Mead J, Gaensler EA 1959 Esophageal and pleural pressures in man, upright and supine. J Appl Physiol 14:81-83

2. Daly WJ, Bondurant S 1963 Direct measurement of respiratory pleural pressure changes in normal man. J Appl Physiol 18:513-518

3. Milic-Emili J, Petit JM 1959 Relationship between endoesophageal and intra-thoracic pressure variations in dog. J Appl Physiol 14:535-537

4. Baydur A, Behrakis PK, Zin WA, Jaeger M, Milic-Emili J 1982 A simple method for assessing the validity of the esophageal balloon technique. Am Rev Respir Dis 126:788-791

5. Baydur A, Cha EJ, Sassoon CSH 1987 Validation of esophageal balloon technique at different lung volumes and postures. J Appl Physiol 62:315-321

6. Thomson A, Silverman M 1983 Pulmonary compliance in sick low birthweight infants. Arch Dis Child 58:891-896

7. Heaf DP, Turner H, Stocks J, Helms P 1986 The accuracy of esophageal pressure measurements in convalescent and sick intubated infants. Pediatr Pulmonol 2:5-8

8. Asher MI, Coates AL, Collinge JM, Milic-Emili J 1982 Measurement of pleural pressure in neonates. J Appl Physiol 52:491-494

9. Coates AL, Davis GM, Vallinis P, Outerbridge EW 1989 Liquid-filled esophageal catheter for measuring pleural pressure in preterm neonates. J Appl Physiol 67:889893

10. LeSouef PN, Lopes JM, England SJ, Bryan MH, Bryan AC 1983 Influence of chest wall distortion on esophageal pressure. J Appl Physiol 55:353-558

11. Sackner MA, Watson H, Belsito AS, Feinerman D, Suarez M, Gonzalez G, Bizousky F, Kreiger B 1989 Calibration of respiratory inductive plethysmograph during natural breathing. J Appl Physiol 66:410-420

12. Sackner MA, Gonzalez H, Rodriguez M, Belsito A, Sackner DR, Grenvik S 1984 Assessment of asynchronous and paradoxic motion between rib cage and abdomen in normal subjects and in patients with chronic obstructive pulmonary disease. Am Rev Respir Dis 130:588-593

13. Lorino N, Lorino AM, Harf D, Atlan G, Laurent D 1982 Linear modeling of ventilatory mechanics during spontaneous breathing. Comput Biomed Res 15:129155

14. Silva-Neto G, Gerhardt T, Silberberg A, Gerhardt T, Claure N, Duara S, Bancalari E 1992 Nonlinear pressure/volume relationship and measurements of lung mechanics in infants. Pediatr Pulmonol 12:146-152

15. Gupta SK, Wagener JS, Erenberg A 1990 Pulmonary mechanics in healthy term neonates: variability in measurements obtained with a computerized system. J Pediatr 117:603-06

16. Ratjen FA, Wiesemann HG 1992 Variability of dynamic compliance measurements in spontaneously breathing and ventilated newborn infants. Pediatr Pulmonol 12:73-80

17. Coates Al, Stocks J 1991 Esophageal pressure manometry in human infants. Pediatr Pulmonol 11:350-360

18. Bhutani KV, Sivieri E, Abassi S, Shaffer T 1988 Evaluation of neonatal pulmonary mechanics and energetics: a two factor least mean square analysis. Pediatr Pulmonol 4:150-158

19. Mammel MC, Fisher JB, Bing DR, Gatto CW, Boros SJ 1990 Effect of spontaneous and mechanical breathing on dynamic lung mechanics in hyaline membrane disease. Pediatr Pulmonol 8:222-225 